\title{
Reinventing the algometer: Synopsis of the literature and presentation of a reliable, inexpensive model
}

\author{
AVIE J. RAINWATER III \\ McLeod Regional Medical Center, Florence, South Carolina \\ and \\ DANIEL W. MCNEIL \\ Oklahoma State University, Stillwater, Oklahoma
}

\begin{abstract}
This article summarizes the historical development of the algometer in scientific investigations and notes hallmarks in the evolution of the device. The algometer has served as a safe nociceptive stimulus for more than a century. Although the earliest renditions were inexpensive, they were often unreliable and difficult to operate. More modern versions have brought reliability, but at increased expense and complexity. Newer versions have failed to make the device easy enough to use to be practical. The "reinvented" algometer is reliable, less expensive than commercial devices, and easy to build and use. These improvements should allow greater application of the algometer in empirical research and assessment of pain.
\end{abstract}

The problems of creating a reliable, easy, and safe technique for producing pain for experimental purposes are evidenced by the more than 80 methodologies presented in the literature since 1943 (see Goetzl, Burrill, \& Ivy, 1943). Myriad attempts to produce a workable device have typically involved stimulation of a chemical, electrical, thermal, or mechanical nature. An instrument that applies pressure to produce and assess pain is commonly referred to as a pressure algometer, although it is sometimes called " Cattell's Algometer' (Head \& Holmes, 1911). According to Keele (1954), "this well established instrument [was] used as far back as the Victorian days"' (p. 636) and best meets the need for a nociceptive instrument that is simple to use and appears as nonnoxious to the subject as possible.

This synopsis looks at the historical development of the pressure algometer and the ways it has been utilized in the exploration of the psychophysical mechanisms of pain perception. This discussion of algometry will be limited to mechanical devices involving cutaneous or deep somatic pressure.

\footnotetext{
This article is supported in part through a fellowship (G0087-10566-88) granted to the first author by the United States Department of Education. The authors would like to express appreciation to Morris W. Gadberry for his technical assistance in the building and redesigning of the algometer. Correspondence should be addressed to Avie J. Rainwater III, Assistant Professor of Family Medicine, McLeod Family Medicine Residency Program, 555 East Cheves Street, Florence, SC 29506.
}

\section{Algometer Requirements}

Part of the difficulty in creating an effective instrument stems from the varied requirements a pain device (algometer) must meet to be useful experimentally and clinically. Hardy, Wolff, and Goodell (1952) specified what is needed in an algometer by calling for measurability, controllability, and reproducibility of the stimulus; an adequate range from threshold to ceiling in the clear perception of pain; minimal tissue damage; convenience; and simplicity. These criteria were later expanded (Beecher, 1959 ) to include (1) the availability of applying the stimulus at a body point where individual neurohistological variations are at a minimum and (2) a method of quantification of stimulus responses over time. Finally, the criteria of reliability and the capability of using the device "without the end result being influenced by the experimenter" (Merskey, 1974, p. 97) were added.

The algometers now in use clinically and experimentally have met these criteria (e.g., Fischer, 1986a; Forgione \& Barber, 1971; Jensen, Andersen, Olesen, \& Lindblom, 1986). The criterion of noninfluence by the experimenter has been relaxed by some researchers, and such influence has been manipulated constructively as an independent variable to test the effect of instructional sets (Dougher, 1979; Gelfand, 1964; Spanos, Barber, \& Lang, 1969) and anxiety types (Dougher, Goldstein, \& Leight, 1987; Haslam, 1966; Malow, 1981) on pain perception and response.

\section{Device Styles and Quantification}

The problem of quantifying stimulation contributed to the evolution of the pressure algometer. Although Cattell's 
algometer (Head \& Holmes, 1911) evidently had no objective method of measurement and relied on the experimenter's subjective assessment, varying device styles have been tried in an effort to produce a unit that is easy to use while still allowing an adequate method of quantification. Two mechanical solutions to this problem emerged. One applied constant pressure to the skin and counted the number of seconds that elapsed before pain threshold or tolerance. The other applied ever increasing weight to the skin and determined how much pressure was needed to reach pain threshold or tolerance.

The amount of pressure applied in Eddy's (1932) device was controlled by a spring-loaded arm that was cranked down to apply pressure to a platform. Turning the crank moved a marker on a scale that had "been graduated by the application of known weights to the spiral spring and read(s) to the half kilogram" (p. 344). The subjective report of the experimenter was used by Libman (1934), who had the experimenter judge how hard the thumb was pressed into the styloid to produce pain.

Spring style. The most common early appearance of the spring-style device was a plunger rod with a flat circular end attached to some form of a hand-held graduated spring obtained from a weighing device (Haslam, 1967; Head \& Holmes, 1911; Keele, 1954; Merskey, Gillis, \& Marszalek, 1962; Merskey \& Spear, 1964; Patkin, 1970). These spring gauges, typically calibrated in kilograms, were most often based on the idea introduced by Keele (1954). McCarty and colleagues (McCarty, Gatter, \& Phelps, 1965; McCarty, Gatter, \& Steele, 1968) devised a special application of this design to quantify articular tenderness. The "analgesiometer" (Clutton-Brock, 1957) also used a spring gauge but did so by attaching the plunger bar to one side of a scale balance.

Dial-gauge style. Several instruments relying on dial gauges have also been tried. The amount of cuff pressure generated was the dependent measure in a sphygmomanometer device that included a metal grater (similar to that used in kitchens) sewn into the cuff (Hollander, 1939). This technique was later made more aggressive by Poser (1962), who replaced the grater with 94 point projections attached to a plastic base. This alteration, however, tended to leave marks on the subject's arm that persisted for several days. A dial-type measure was used by Pelner (1941) in his "sensometer." This dial was actually a watch with a rod attached to the workings so that the hands would move when pressure was applied to the rod. This device was hand-held and typically pressed into the proximal phalanx of the subject's thumb. The sphygmomanometer gauge concept was revived by Harrison and Bigelow (1943) in their modification of Lewis's (1942) ischemic pain test. An air-pressure gauge was used in the "dolorimeter" (Gluzek, 1944) to ascertain how much pressure two disks exerted against the subject's skin.

More recently, Fischer (1981) introduced a dial-based instrument for evaluation of soft-tissue pathology. This device has changeable tips that allow a variety of applications from trigger-point measurement (Fischer \& Chang, 1986) to pressure tolerance over muscles and bones (Fischer, 1986b).

Similar to Fischer's (1981) device, the pen-style algometer presented by Jensen, Andersen, Olesen, and Lindblom (1986) is also hand-held and has changeable tips. However, although the mechanism of measurement is by means of a strain gauge, quantification is achieved through an amplified signal connected to a pen recorder. This method of data acquisition is basically the same as that employed by Forgione and Barber (1971).

Blade style. The most elaborate method of quantification uses a pressure transducer that is calibrated and attached to a polygraph for measurement of the pressure amount (Forgione \& Barber, 1971). This "focal pain stimulator" calls for the finger to be secured in a trough while a weighted blade, attached with a hinge to the end of the trough, is lowered onto the second phalanx of the finger. The blade is attached to the transducer, which is in turn connected to a polygraph that permits serial recording of pressure data. This algometer has had its most significant impact less for its use of the serial data collection afforded by the polygraph than for its use of a standard weight to apply a constant pressure. This device, and several modifications of it, has been extensively utilized (Dougher, 1979; Dougher, Goldstein, \& Leight, 1987; Malow, 1981; Malow \& Dougher, 1979; Malow, Grimm, \& Olson, 1980; Malow \& Olson, 1981; Malow, West, \& Sutker, 1987; Otto \& Dougher, 1985).

Comment. Few of the devices listed above are actually available for purchase-most must be built by an instrument maker. The "pressure threshold meter" (Fischer, 1986a; Reeves, Jaeger, \& Graf-Radford, 1986), however, is commercially produced (Pain Diagnostics and Thermography, 17 Wooley Lane East, Great Neck, NY 11021). This device is a sophisticated modification of the Geneva Lens measure used by Pelner (1941). It is hand-held and has a circular dial (available with different calibrations and rod tips for different applications) that moves in response to the amount of manual pressure applied by the experimenter/ clinician. Thus, this device offers a unique blend of old and new. The instrumentation and mechanical workings are highly reliable and sensitive, yet the device is still somewhat dependent on the skill of the user in placement of the pressure tip and smoothness of the application of pressure. The same is true of another commercially available variable pressure device (John Chatillon and Sons, 7609 Business Park Drive, Greensboro, NC 27409; FAX: 919/665-9163).

Although this dependence may be acceptable for clinical applications, it may not be desirable in experimental situations. The algometer described below can be built for under $\$ 25$, which is inexpensive compared with commerical devices that sell in the $\$ 300$ range. The use of a constant weight eliminates stimulus subjectivity and makes it acceptable for use in experimentation. Additionally, the re- 
Table 1 Materials List for Algometer

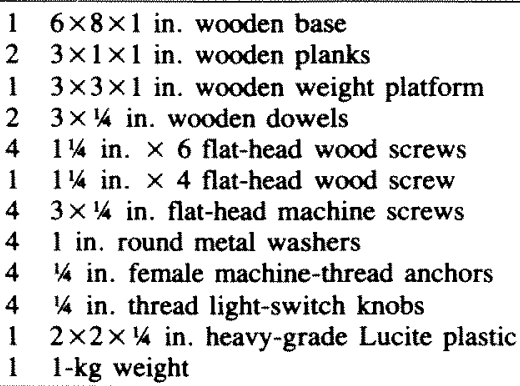

liability of this design has been established through more than 300 consecutive failure-free experimental applications (see Rainwater \& McNeil, 1986, 1990).

\section{CONSTRUCTION}

\section{Materials}

Materials for construction of the algometer are listed in Table 1.

Any type of wood may be used, but a hardwood is recommended to increase the algometer's durability. The pegs of the weight platform sustain much use as the platform is placed on and off the base and are subject to break- age. Therefore, a dowel of $1 / 4$-in. $(6.25-\mathrm{mm})$ diameter or greater is recommended.

Machine-threaded nut anchors with base points that press into the wood are superior to anchors without such securing nibs, which tend to loosen over time and turn when the thumbscrew is turned. The center hole of the washer facilitates soldering the washer to the flat head of the screw. Although more decorative knobs may be used, table-lamp-switch replacement knobs can be found at any hardware store. Most hardware stores carry heavy Lucite plastic or Plexiglas shim stock. A kilogram weight may be purchased from a scientific supply house, or one can be easily made.

\section{Procedure}

A base is cut $150 \mathrm{~mm}$ wide, $250 \mathrm{~mm}$ long, and $25 \mathrm{~mm}$ high from hardwood. Two hardwood planks are then cut $100 \mathrm{~mm}$ long, $10 \mathrm{~mm}$ wide, and $20 \mathrm{~mm}$ high. As can be seen in Figure 1, a $45^{\circ}$ angle is cut at the end of each plank to allow the hand greater ease when a finger is placed in the trough of the algometer and the other fingers are separated around the planks.

Two $1 / 4-$ in. $(6.25-\mathrm{mm})$ holes are then drilled into the side of each plank in preparation for the female machinethread anchors. The placement of these holes is given in Figure 2. The anchors are then driven into place; a small amount of wood glue serves as a good lubricant
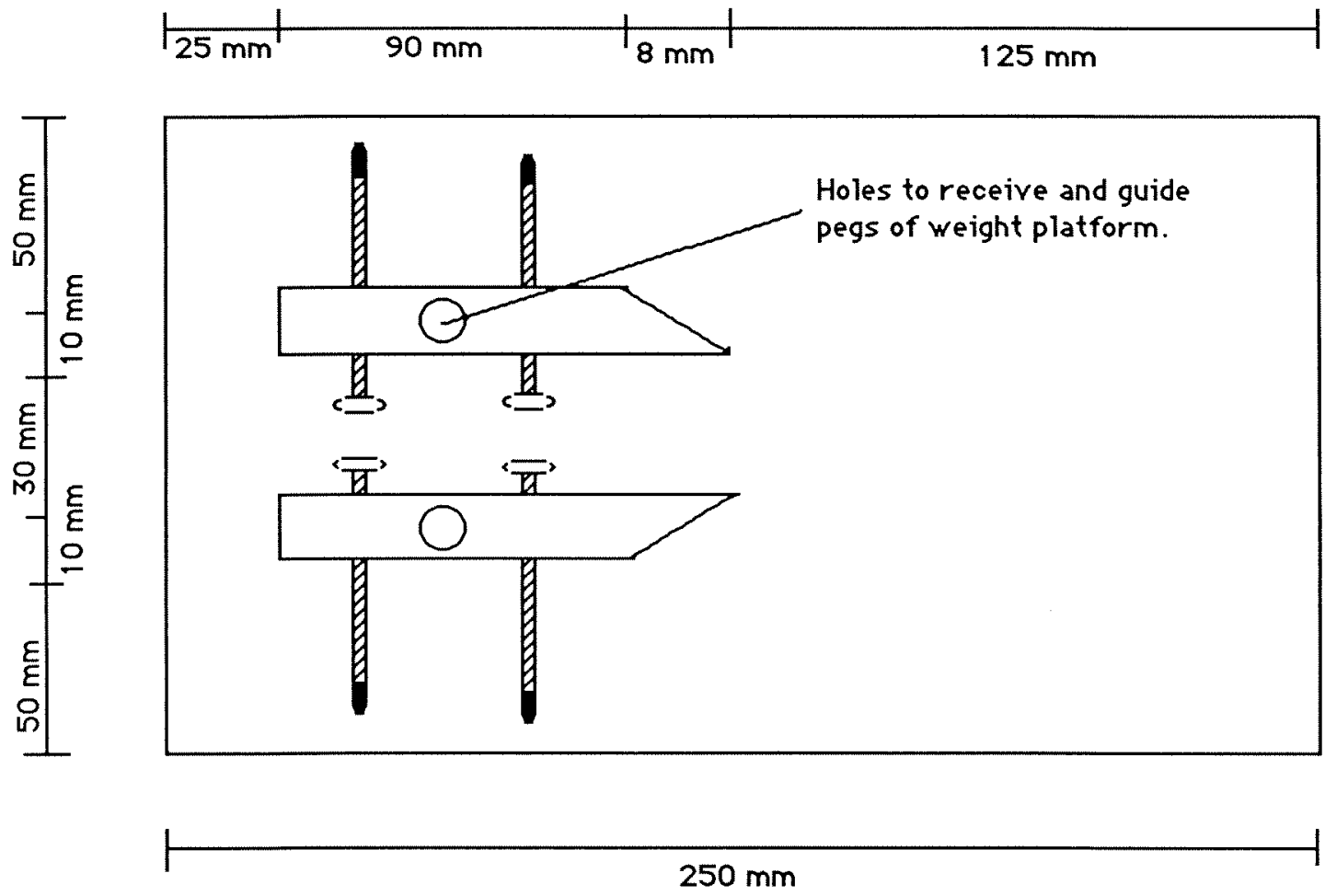

Top View

Figure 1. Top view of the algometer. 

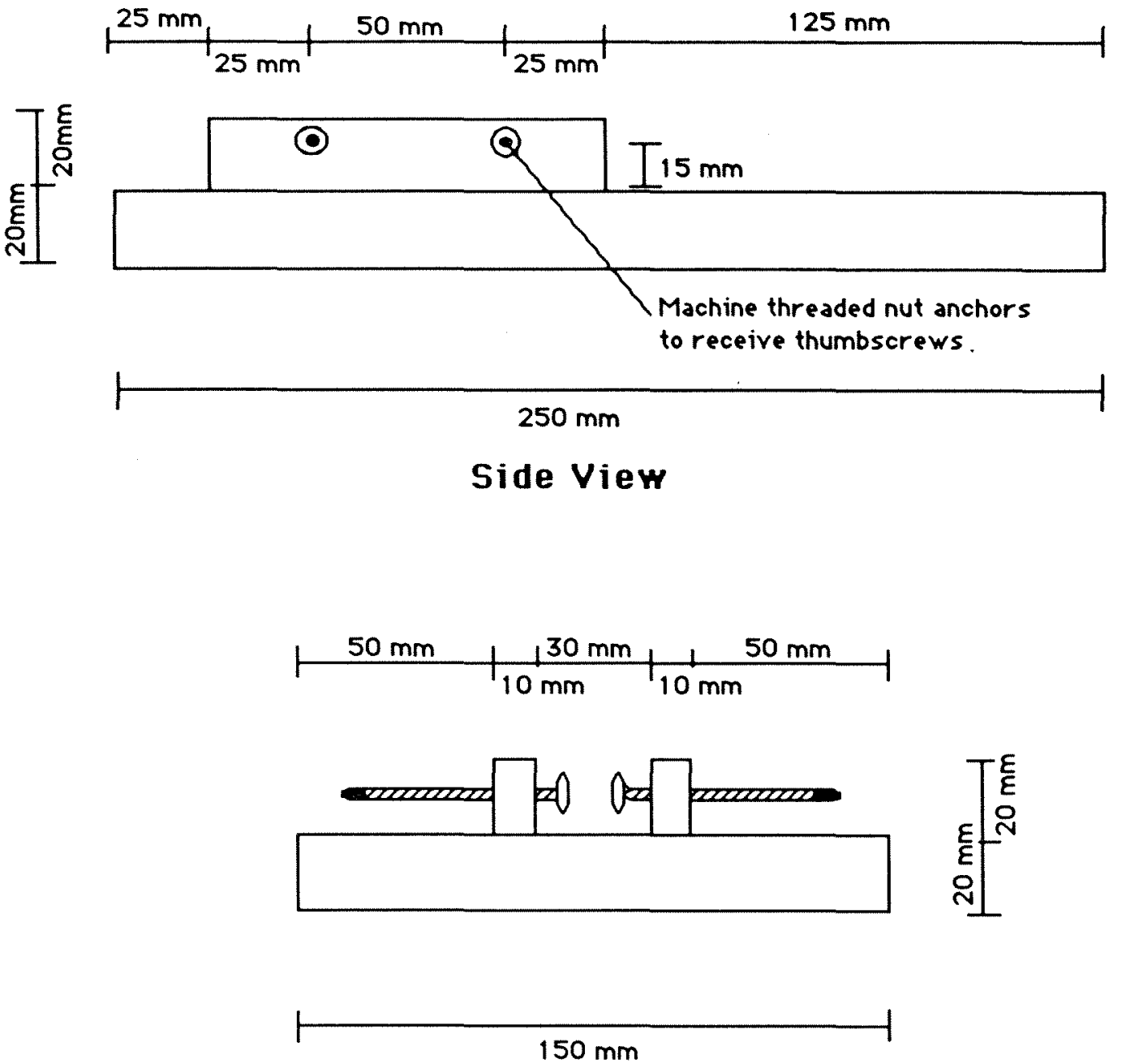

Front View

Figure 2. Side and front views of the algometer.

for this purpose and helps prevent the anchors from slipping with wear.

The washers are then soldered onto the heads of $50 \mathrm{~mm}$ $\times 1 / 4$ in. $(6.25-\mathrm{mm})$ machine screws to form the thumbscrews (see Figure 3 ). These screws should be placed in the anchors before the planks are fastened to the base. The knobs may be added at any time.

The planks are attached from the bottom of the base using $1 \frac{1 / 4}{4}$ in. $(31.25 \mathrm{~mm}) \times 6$ flat-head wood screws. A small amount of wood glue should be placed on the bottom of the planks to ensure that they are securely attached to the base. The planks should be positioned as shown in Figure 1 so that a $30-\mathrm{mm}$ trough is left between the planks. The wood screws should be countersunk on the bottom of the base and the countersink filled with wood putty.

Next, the weight platform (see Figure 3) should be cut $80 \mathrm{~mm}$ wide, $80 \mathrm{~mm}$ long, and $30 \mathrm{~mm}$ deep. One-quarterinch $(6.25-\mathrm{mm})$ holes are then drilled into the appropriate places in the platform and on the planks. The pegs are then glued into place in the platform. The dowels may need to be sanded to assure ease of movement in and out of the holes of the base planks.

The Lucite is then cut into a $25 \times 25 \mathrm{~mm}$ square (height $x$ width) blade, $10 \mathrm{~mm}$ deep. With the use of a grinder, an edge is then formed on the blade. The edge should form two $45^{\circ}$ angles and be approximately $2.5 \mathrm{~mm}$ at its apex and approximately $10 \mathrm{~mm}$ thick. Next, the blade is attached lengthwise between the dowel pegs of the platform with a $1 \frac{1 / 4}{4}$ in. $\times 4$ flat-head wood screw inserted through the top of the platform and into the flat, top portion of the blade. A shallow tap hole should be drilled into the flat, top portion of the blade to help prevent the Lucite from cracking when it is screwed to the platform. Alternatively, two screws may be added for stability; for additional security, a groove may be cut into the bottom of the platform and the blade inserted into the groove. With 


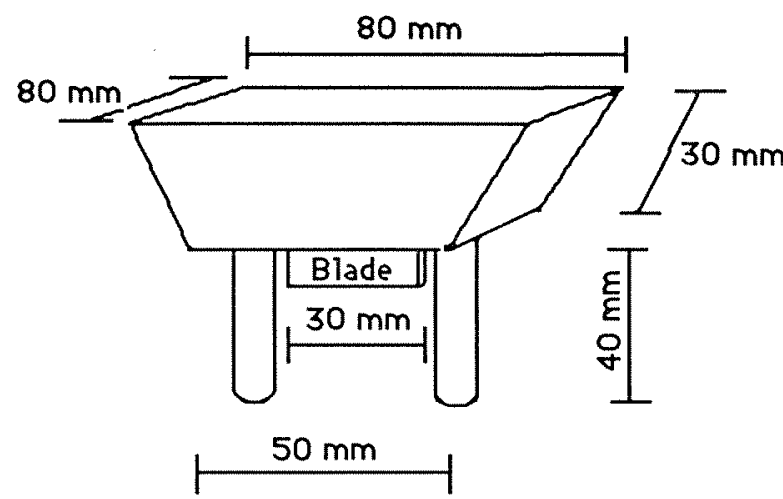

Platform

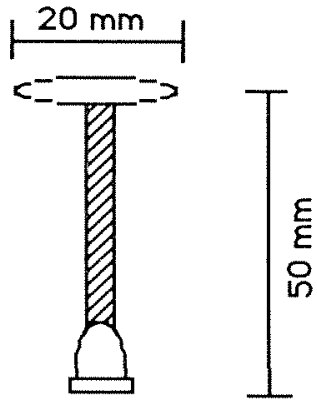

Thumbscrew

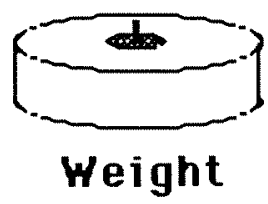

Figure 3. Diagrams of the algometer weight platform and thumbscrew.

either of these methods, a small amount of glue should be used.

Finally, sealant should be applied to the wood to protect it from wear. This also is necessary to prevent the algometer from becoming stained with palmar sweat. A top view of the finished product shows a subject's finger in the device with the platform in place and the weight applied (see Figure 4).

\section{DISCUSSION}

The algometer is used by placing a finger in the trough that is then held secure as the plank thumbscrews are lightly fastened against it. Next, the platform is inserted into the base so that the blade touches the finger in an area of skin sparse in muscle and fat and directly over bone (i.e., second phalanx of the finger). When a trial is to begin, the weight is placed onto the platform. Over time, pain will develop as the weight presses into the finger. The trial is over when the subject asks to have the weight removed or when $4 \mathrm{~min}$ have elapsed (Rainwater \& McNeil, 1990).

Several different time-based measures may be obtained with this methodology (see Rainwater \& McNeil, 1990). Subjects are requested to respond using the following scale based on one developed by Otto and Dougher (1985): $1=$ mild pressure, 2 = moderate pressure, 3 = mild discomfort, $4=$ moderate discomfort, $5=$ mild pain, $6=$ moderate pain, 7 = severe pain. The pain threshold is taken to be that amount of time required for subjects to give the first rating of 5 or better. The pain ceiling is that amount of time taken to elicit a rating of 7 . When subjects report a 7 , they can be asked to hold that sensation. The length of time subjects are willing to endure a 7 level of pain is taken to be the pain tolerance.

Research involving pain requires special attention to ethical issues. Studies using an algometer should receive Institutional Review Board review to specifically address concerns about social coercion, physical risk, and so forth. We have dealt with the physical harm dilemma by adopting the maximum time limit given above to protect the physical integrity of the subject's finger. Although somewhat longer time limits may be medically acceptable, this more conservative limit is suggested to hold risk at a minimum (see American Psychological Association, 1990, Principle 9). To avoid a demand set wherein subjects might continue in the condition beyond the point of personal comfort, we have used instructions that follow a lowdemand style (Miller \& Bernstein, 1972) to readily allow avoidance. Safety is also addressed by the design of the device, which allows subjects to quickly and easily remove the weight themselves if they so desire. Providing this option is important, especially for subjects who might be unwilling to ask for the pressure to be terminated by the experimenter.

The "reinvented" algometer described in this paper is easy to build and use. It meets all stated criteria for use as a reliable device (Beecher, 1959; Hardy, Wolff, \& Goodwell, 1952; Merskey, 1974) and offers the benefits 


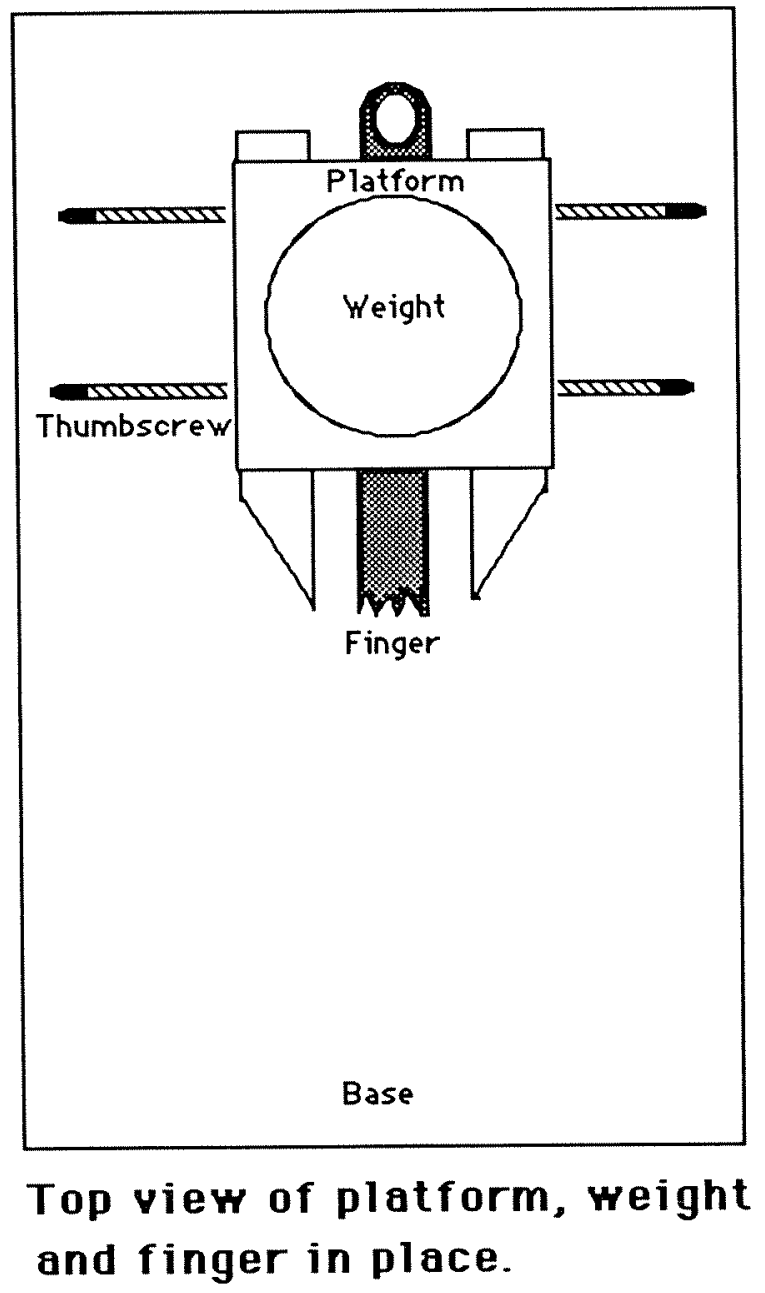

Figure 4. Top view of algometer with platform, weight, and finger in place.

of low-cost construction and ease of operation. This algometer has been successfully used clinically by the first author in transactional psychophysiological assessments with pain patients.

\section{REFERENCES}

American Psychological Association. (1990). Ethical principles of psychologists. American Psychologist, 45, 390-395.

BEECHER, H. K. (1959). Measurement of subjective responses. New York: Oxford University Press.

Clutton-Brock, J. (1957). The cerebral effects of over-ventilation. British Journal of Anaesthesiology, 29, 111-113.

Dougher, M. J. (1979). Sensory decision theory analysis of the effects of anxiety and experimental instruction on pain. Journal of $A b$ normal Psychology, 88, 137-144.

Dougher, M. J., Goldstein, D., \& LeIGHT, K. A. (1987). Induced anxiety and pain. Journal of Anxiety Disorders, 1, 259-264.

EDDY, N. B. (1932). Studies on morphine, codeine, and their derivatives. Journal of Pharmacology \& Experimental Therapeutics, 45. 339-359.

Fischer, A. A. (1981). Tissue compliance recording: A method for objective documentation of soft tissue pathology. Archives of Physical Medicine \& Rehabilitation, 62, 542.

Fischer, A. A. (1986a). Pressure threshold meter: Its use for quantification of tender spots. Archives of Physical Medicine \& Rehabilitation, 67, 836-838.

Fischer, A. A. (1986b). Pressure tolerance over muscles and bones in normal subjects. Archives of Physical Medicine \& Rehabilitation, 67, 406-409.

Fischer, A. A., \& Chang, C. H. (1986). Temperature and pressure threshold measurement in trigger points. Thermology, 1, 212-215.

Forgione, A. G., BARBER, T. X. (1971). A strain gauge pain stimulator. Psychophysiology, 8, 102-106.

GelfaND, S. (1964). The relationship of experimental pain tolerance to pain threshold. Canadian Journal of Psychology, 18, 36-42.

Gluzek, L. J. B. (1944). Dolorimetry: A quantitative method of measuring pain and deep sensitivity. Ohio State Medical Journal, 40, 49-50.

GOETZL, F. R., BURRILL, D. Y., \& IVY, A. C. (1943). Methods of testing pain sensitivity. Quarterly Bulletin of the Northwestem University Medical School, 17, 280-291.

Hardy, J. D., WolfF, H. G., * Goodell, H. (1952), Pain sensations and reactions. Baltimore: Williams \& Wilkins.

HARRISON, I. B., Bigelow, N. H. (1943). Quantitative studies of visceral pain produced by the contraction of ischemic muscle. Proceed ings of the Association of Research of Nervous \& Mental Disorders, 23, 134-165.

HASLAM, D. R. (1966). The effect of threatened shock upon pain threshold. Psychonomic Science, 6, 309-310.

HASLAM, D. R. (1967). Individual differences in pain threshold and level of arousal. British Journal of Psychology, 58, 139-142.

Head, H., Holmes, G. (1911). Sensory disturbances from cerebral lesions. Brain, 34, 102-254.

Hollander, E. (1939). A clinical gauge of sensitivity to pain. Journal of Laboratory \& Clinical Medicine, 24, 537-538.

Jensen, K., ANDersen, H. D., Olesen, J. \& Lindblom, U. (1986). Pressure-pain threshold in human temporal region: Evaluation of a new pressure algometer. Pain, 25, 313-323.

Keele, K. D. (1954). Pain-sensitivity tests: The pressure algometer. Lancet, 266, 636-639.

LEWIs, T. (1942). Pain. New York: MacMillan.

Lrbman, E. (1934). Observations on individual sensitivities to pain. Journal of the American Medical Association, 102, 335-341.

MaLow, R. M. (1981). The effects of induced anxiety on pain perception: A signal detection analysis. Pain, 11, 397-405.

Malow, R. M., \& Dougher, M. J. (1979). A signal detection analysis of effects of transcutaneous stimulation in pain. Psychosomatic Medicine, 41, 101-108.

MaLow, R. M., Grimm, L., * OLSON, R. E. (1980). Differences in pain perception between myofascial pain dysfunction patients and normal subjects: A signal detection analysis. Journal of Psychosomatic Research, 24, 303-309.

Malow, R. M., \& OLson, R. E. (1981). Changes in pain perception after treatment of chronic pain. Pain, 11, 65-72.

Malow, R. M., West, J. A., \& SutKer, P. B. (1987). A sensory decision theory analysis of anxiety and pain responses in chronic drug abusers. Journal of Abnormal Psychology, 96, 184-189.

McCarty, D. J., Gatter, R. A., \& Phelps, P. (1965). A dolorimeter for quantification of articular tenderness. Arthritis \& Rheumatism, 8, 551-559.

McCarty, D. J., Gatter, R. A., \& Steele, A. D. (1968). A twenty pound dolorimeter for quantification of articulary tenderness. Arthritis \& Rheumatism, 11, 696-698.

Merskey, H. (1974). Assessment of pain. Physiotherapy, 60, 96-98.

Merskey, H., Gillis, A., \& Marszalek, K. S. (1962). A clinical investigation of reactions to pain. Journal of Mental Science, 108, 347-355.

Merskey, H., SPEAR, F. G. (1964). The reliability of the pressure algometer. British Journal of Social \& Clinical Psychology, 3, 130-136.

Miller, B. V., BERNSTEIN, O. A. (1972). Instructional demand in 
a behavioral avoidance test for claustrophobic fears. Journal of $A b$ normal Psychology, 80, 206-210.

Otro, M. W., \& Dougher, M. J. (1985). Sex differences and personality factors in responsivity to pain. Perceptual \& Motor Skills, 61, 383-390.

PATKIN, M. (1970). Measurement of tenderness with the description of a simple instrument. Medical Journal of Australia, 1, 670-672.

Pelner, L. (1941). The determination of sensitivity to pain. Journal of Laboratory \& Clinical Medicine, 27, 248-251.

POSER, E. G. (1962). A simple and reliable apparatus for the measurement of pain. American Journal of Psychology, 75, 304-305.

RaINwater, A. J., \& MCNeIL, D. W. (1986, April). Interrelationships between fear of pain and fear of bodily mutilation. Poster presented at the meeting of the Southwestern Psychological Association, Ft. Worth.
RAINWATER, A. J., MCNeIL, D. W. (1990). The role of experienced pain in the assessment of fear of pain: A predictive validity study of the Fear of Pain Questionnaire - III. Manuscript in preparation.

ReEves, J. L., JAEGER, B., \& Graf-RADFord, S. B. (1986). Reliability of the pressure algometer as a measure of myofascial trigger point sensitivity. Pain, 24, 313-321.

Spanos, N. P., Barber, T. X., \& Lang, G. (1969). Cognition and self control: Cognitive control of painful sensory input. In $\mathrm{H}$. London \& R. Nisbett (Eds.), Cognitive alteration of feeling states. Chicago: Aldine.

(Manuscript received June 8, 1990; revision accepted for publication June 3,1991.)

\section{Third Annual Conference on Computing for the Social Sciences University of Michigan, Ann Arbor May 4-7, 1992}

\section{CALL FOR PAPERS}

The third conference on Computing for the Social Sciences-sponsored by the Social Sciences Computing Association in cooperation with the Bureau of the Census and Oak Ridge National Laboratory-will be held at the University of Michigan, Ann Arbor, May 4-7, 1992.

The focus of the conference will be on the revolutionary capabilities for the management and analysis of social, economic, political, and demographic data brought about by the technological changes of recent year. The program will follow five major tracks: (1) data acquisition, management, and distribution; (2) research strategies and analytic methods; (3) graphics and visualization; (4) infrastructure; and (5) networks. Any of these tracks may include special topics such as teaching methods, international collaboration, ethics and values, PCs/Macs, supercomputing, operating systems, and user interfaces.

The deadline for the submission of abstracts is December 1, 1991. The deadline for sending full text of selected papers is April 1, 1992.

The conference fee will be $\$ 200$, and registration materials will be mailed in January.

For further information, contact the program chairman, Al Anderson, at the University of Michigan (Phone: 313-998-7140 - Fax: 313-998-7415 - Internet: albert_f._anderson@um.cc.umich.edu and BITNET: UserLD52@umichum 